\title{
Gallbladder Adenocarcinoma
}

National Cancer Institute

\section{Source}

National Cancer Institute. Gallbladder Adenocarcinoma. NCI Thesaurus. Code C9166.

An adenocarcinoma arising from the gallbladder. It is the most common malignant tumor of the gallbladder and it is usually well to moderately differentiated. The incidence is higher in patients with gallstones than in patients without gallstones. Signs and symptoms usually present late in the course of the disease and are reminiscent of those of chronic cholecystitis including right upper quadrant pain. Histologic variants include adenocarcinoma of the intestinal type, clear cell adenocarcinoma, mucinous adenocarcinoma, papillary adenocarcinoma, and signet ring adenocarcinoma. 